Revue d'histoire de l'Amérique française

ZWB REVUE D.HISTOIRE DE L'AMÉRIQUE FRANÇAISE

\title{
Éclaircissements inédits de Faillon sur son Histoire de la colonie française
}

Volume 5, numéro 4, mars 1952

URI : https://id.erudit.org/iderudit/802138ar

DOI : https://doi.org/10.7202/802138ar

Aller au sommaire du numéro

Éditeur(s)

Institut d'histoire de l'Amérique française

ISSN

0035-2357 (imprimé)

1492-1383 (numérique)

Découvrir la revue

Citer ce document

(1952). Éclaircissements inédits de Faillon sur son Histoire de la colonie française. Revue d'histoire de l'Amérique française, 5(4), 585-588.

https://doi.org/10.7202/802138ar d'utilisation que vous pouvez consulter en ligne.

https://apropos.erudit.org/fr/usagers/politique-dutilisation/ 


\section{ECLAIRCISSEMENTS INÉDITS DE FAILLON}

SUR SON Histoire de la colonie française*

I - Lettre de Faillon au cardinal Clément de Villecourt

pour avoir accès aux archives de la Sacrée Congrégation de la Propagande, a Rome

Eminence,

Aix-en-Provence, le 4 décembre 1862

Après un dernier séjour de cinq ans en Amérique, je suis revenu en France au mois de juillet, pour assister à notre assemblée générale, du résultat de laquelle Votre Eminence a été informée, par la Supplique que vous avez daigné présenter à Notre Saint Père le Pape. Je pensais continuer à Paris l'histoire religieuse et civile du Canada, dont on m'a charge depuis plusieurs années, et qui avait été cause, en partie, de mon troisième voyage en Amérique. Mais une affection au genou, que j'avais éprouvée autrefois en France, s'étant reproduite, dès le lendemain de mon retour a Paris, et m'ayant retenu dix semaines dans ma chambre, sans me permettre de monter au Saint Autel; on m'a envoyé au Séminaire d'Aix, où l'on espère que l'air plus sec et plus chaud que celui de Paris, me sera fa-

\footnotetext{
* Documents fournis par le R.P. Conrad Morin, o.f.m.
} 
vorable, comme il l'a êté en effet depuis près de trois mois que j'y suis 6tabli.

Pour composer mon histoire, j'ai fait beaucoup de recherches dans les divers dépôts d'archives du gouvernement français, dans les Bibliothèques de Paris, à celle de Londres; enfin, en Canada à Québec, Montréal et ailleurs. Je pensais avoir tout exploré, lorsque j'apprends qu'on conserve à Rome, dans les archives de la Sacrée Congrégation de la Propagande, beaucoup d'anciens documents relatifs à l'histoire ecclésiastique du Canada; et je ne voudrais pas terminer mon travail sans savoir s'il me serait permis d'en prendre connaissance.

Je sais que difficilement on pénètre dans ces dernières archives, et que tout dernièrement on a eu à se repentir d'en avoir permis l'entrée trop facilement. Je ne puis pas juger si la bonne volonté, dont il me semble que j'ai donné jusqu'ici des preuves, en défendant les traditions et l'honneur du Saint-Siège, serait un titre à alléguer pour inspirer toute confiance et obtenir cette permission. Mais ce que je puis assurer, c'est qu'ayant pour fin dans mon Histoire, de fortifier la jeunesse canadienne dans l'attachement au Saint-Siège Apostolique, en rappelant à la génération prósente les souvenirs oubliés du passé: je serais ravi de parcourir ces anciens documents, où je présume que je pourrais trouver bien des traits précieux qu'on chercherait vainement ailleurs.

C'est, Monseigneur, le motif qui me fait prendre la liberté de m'adresser à Votre Eminence, pour lui exposer simplement ma pensée, en la priant de ne point y donner de suite, si Elle la jugeait inopportune, ou indiscrète.

Daignez agréer, Monseigneur, les sentiments de Vénération profonde avec lesquels je serai toujours en Notre Seigneur et sa divine Mère de Votre Eminence le très humble et très obéissant fils et serviteur

(signe) Faillon, ptre, au Grand Séminaire d'Aix-en-Provence.

(Arch. S.C. Prop. (Rome). Scritture riferite nei Congressi: America Settentrionale 8 (1862-1865), fol. 453-454. Original.)

II - Lettre du cardinal de Villecourt au cardinal Barnabo, préfet de la S.C. de la Propagande, pour obtenir l'accès aux archives de celle-ci en faveur de Faillon

Eminence,

Rome, le 11 décembre 1862

La lettre ci-jointe est de M. l'abbé Faillon, pieux et savant auteur de la Vie de M. Olier et des Monuments inédits sur Ste Magdeleine.

Je suis persuadé que si on lui permettait de venir prendre à Rome communication des pièces qui dans la bibliothèque de la Propagande 
regardent le Canada il n'en userait que pour l'honneur de la Ste Église. D'ailleurs, sa sainteté bien connue est une garantie contre la crainte que la moindre des pièces ne soit détournée.

Un oui ou un non de Votre Eminence déterminera ou détournera le Voyage de M. Faillon à Rome.

Je lui baise humblement les mains, en lui offrant mes sentiments les plus respectueux et les plus dévoués. (signê) † Clém. Card. Villecourt

(Arch. Prop. - Ibid., fol. 450. Original.)

III - Lettre de Faillon au cardinal Barnabo, Préfet de la S.C. de la Propagande au sujet de la vue prophétique de M. Olier sur la Colonie de Montréal

Eminence,

Rome, [ octobre 1865 ]

Vous avez eu l'extrême complaisance de me remettre en mémoire hier soir, les Vues de Mr Olier sur le grand Saint Denis. Ces vues ne sont pas, comme je le disais, les seules vues surnaturelles, ou comme les appelle Votre Eminence les seules révélations, que Mr Olier ait eues; et si vous voulez bien me le permettre, je mettrai sous vos yeux une autre vue surnaturelle, qui a eu pour objet la colonie de Montréal, avant même que la colonie fut établie?

Votre Éminence veut bien s'occuper actuellement de ce pays: je prends done la liberté de lui offrir l'ouvrage joint à cette lettre, où la vue prophétique dont je parle est exposée par Mr Olier lui-même, à la page XXIII de l'introduction. La Vie de la Sœur Bourgeoys, que les Sœurs de la Congrégation me prièrent de composer pour elles à l'occasion de mon premier voyage en Canada, est d'ailleurs un épisode de l'histoire de la Colonie Canadienne, dont Votre Éminence a daigné déjà accepter l'hommage; et c'est ce qui me fait prendre la liberté de la lui offrir, ainsi que le renouvellement du profond respect avec lesquels je suis de Votre Eminence le très humble et très dévoué serviteur

(signé) faillon, ptre.

[ Procureur des Sulpiciens à Rome]

[ sur l'endos $=$ fol. $1445 \mathrm{v}$, on lit: ]

America. Canada - Montreal [ Ottobre 1865 ] Il Sacerdote Faillon, Procuratore dei Sulpiziani... [ = résumé de sa lettre ].

(AP - S.C. America Settentrionale 8 (1862-1865): fol. 1444. Original). 
IV - Lettre de Faillon au Préfet de la Propagande sur les écrits algonquins de l'abbé Thavenet

Rome, 19 novembre 1865

Eminence,

J'apprends qu'un de nos confrères du Canada, Missionnaire des Sauvages Algonquins depuis près de 25 ans, demande s'il pourrait avoir communication des ecrits Algonquins que Mr Thavenet a donnés à la Propagande. Mais comme je sais que notre mission du Lac des deux Montagnes possède déjà une copie du dictionnaire Algonquin de Mr Thavenet j'ose demander à Votre Eminence:

1o Quels sont les écrits Algonquins de Mr Thavenet que la Propagande possède?

2o Si l'on pourrait avoir communication de ceux de ces écrits que la Mission du Lac des deux Montagnes ne possederait pas?

Daignez agréer le nouvel hommage des sentiments de respect profond avec lesquels je suis

de Votre Eminence...

Rome, 19 nov. 1865. S. Venanzio, 3.

(signe) faillon, ptre

(AP - S.C. America Settentrionale 8 (1862-1865): fol. 1459. Original). 